\title{
STABLE DEEP EUTECTIC SOLVENT DOPED WITH METAL NANOPARTICLES
}

\author{
1,2Anastasiia TULUPOVA, ' Vasilii BURTSEV, '1Vaclav ŠVORČíK, ${ }^{1,2}$ Oleksiy LYUTAKOV \\ ${ }^{1}$ VŠCHT - University of Chemistry and Technology, Prague, Czech Republic, EU, lyutakoo@vscht.cz \\ ${ }^{2}$ Tomsk Polytechnic University, Research School of Chemistry and Applied Biomedical Sciences, Tomsk, \\ Russian Federation
}

https://doi.org/10.37904/nanocon.2021.4340

\begin{abstract}
In this work, we prepared MeNPs doped DES systems. Gold nanoparticles were prepared on aluminum oxide microparticles surface. DES was prepared from choline chloride and urea, and embedded with the nano/micro particles. Created system was characterized using UV-Vis and FTIR spectroscopy, as well as TEM technique. As the result, we demonstrate that stable deep eutectic solvents that can be used for a range of applications.
\end{abstract}

Keywords: Deep eutectic solvents, doped, metal nanoparticles

\section{INTRODUCTION}

Metal nanoparticles (MeNPs) are of high interest since their unique optical, magnetic, electrical and physiological properties [1]. MeNPs can be used in different application areas, such as biomedicine [2], electrochemical catalysis [3], chemical sensing [4] and many others. MeNPs are commonly used as a colloidal suspension in water or traditional organic solvents. In turn, Deep Eutectic Solvents (DES) are recently proposed new alternative media for applications as a "green" reaction medium in organic synthesis. In contrast to traditional organic solvents, DES is non-toxic and non-flammable. Finally, deeply eutectic solvents do not produce toxic metabolites and are biodegradable [5]. The main uses of DES technology include the synthesis of nanostructures with a controlled shape [6], metal electrodeposition [7], $\mathrm{CO} 2$ adsorption [8] and others. But recently, attention has been paid to the study of DES as alternative solvents for organic synthesis and photochemistry. In this work we propose a creation of MeNPs doped DES for a range of potential applications.

\section{EXPERIMENTAL}

\subsection{Materials}

Gold(III) chloride trihydrate (HAuCl4, $\geq 99.9 \%$ ), sodium citrate tribasic dihydrate ( $\geq 99.5 \%$ ), choline chloride $(\geq 98,0 \%)$, urea $(\geq 99,0 \%)$, aluminum oxide, 4-aminothiophenol $(\geq 97,0 \%)$, p-Toluenesulfonic acid monohydrate $(\geq 98,5 \%)$, tert-Butyl nitrite $(\geq 90,0 \%)$, methanol, acetonitrile and deionized water were purchased from Sigma-Aldrich and used without further purification.

\subsection{Samples preparation}

Preparation of Deep eutectic solvent

At first stage, choline chloride is dried under vacuum at $90^{\circ} \mathrm{C}$ and then mixed with powdered urea in a ratio of $1: 2$. The two components were heated with constant stirring until a homogenous mixture was obtained (around 5 hours). 


\section{Preparation of AuNPs}

Gold nanoparticles on aluminum oxide microparticles surface was prepared according to following methodology: $\mathrm{Al}_{2} \mathrm{O}_{3}$ powder first was modified with functional group - $\mathrm{SH}$ using a diazonium salt. Modified $0,2 \mathrm{~g}$ $\mathrm{Al}_{2} \mathrm{O}_{3}$ was added to deionized water and boil. After the water boiled was added $10 \mathrm{mM}$ aqueous $\mathrm{HAuCl}_{4}$ solution to it, then $40 \mathrm{mM}$ sodium citrate tribasic dihydrate water solution was added dropwise within 30-40 seconds. The resulting solution was boiled for $10 \mathrm{~min}$, then was transferred to a cold hotplate and continue stirring for 12 hours. The resulting particles were washed by water and methanol by centrifugation at $7000 \mathrm{rpm}$ for $5 \mathrm{~min}$ and dried in oven at $60{ }^{\circ} \mathrm{C}$. Figure 1 schematically shows the preparation route $\mathrm{Al}_{2} \mathrm{O}_{3}-\mathrm{AuNPs}$.

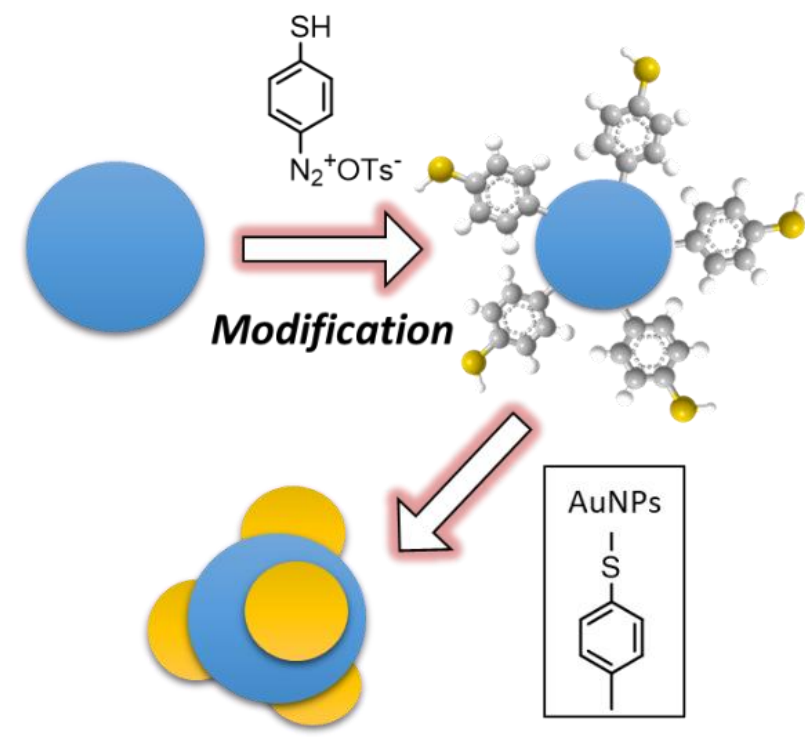

Figure 1 Schematic representation of the preparation of gold nanoparticles on aluminum oxide microparticles surface

\subsection{Measurement Techniques}

UV-Vis absorbance spectra of the samples were measured using a HR2000 (Ocean Optics) spectrometer in 200-800 nm wavelengths range using the AvaLight-DHS light source (Avantes).

Fourier transform infrared (FTIR) attenuated total reflection (ATR) spectra were recorded using a Nicolet 6700 spectrometer (Thermo Scientific, France) with a Smart ATR accessory device (1000 scans and $4 \mathrm{~cm}^{-}$ 1 resolution).

Transmission electron microscopy (TEM) images were obtained with a JEOL JEM-1010 instrument (JEOL Ltd., Japan), with a SIS MegaView III digital camera (Soft Imaging Systems, acceleration voltage $80 \mathrm{kV}$ ) and analysis was performed by using AnalySIS Software 2.0.

\section{RESULTS AND DISCUSSION}

Deep eutectic solvent including choline chloride $(\mathrm{ChCl})$ as the hydrogen bond acceptor urea as a hydrogen bond donor were prepared. The synthesized DES had the following physicochemical properties: a homogenous and transparent liquid of high viscosity, without any evident solid particles and stable at room temperature. To confirm the formation of hydrogen bonding, infrared spectra of choline chloride, urea and deep eutectic solvents were obtained. The results are presented in Figure 2. Absorption bands of urea at $3425 \mathrm{~cm}^{-}$ ${ }^{1}$ and $3333 \mathrm{~cm}^{-1}$ correspond to the stretching mode of $-\mathrm{NH}_{2}$. On the contrary, these absorption bands moved towards the lower values of wavenumber, and specifically $3402 \mathrm{~cm}^{-1}$ and $3315 \mathrm{~cm}^{-1}$. This shift could be affected by the formation of hydrogen bonds between urea and $\mathrm{ChCl}$. Also, the bands associated to $\mathrm{ChCl}$ and urea 
appeared in the spectrum of DES. Their corresponding wave number of the vibrational modes and associated terminal groups are listed in Table 1.

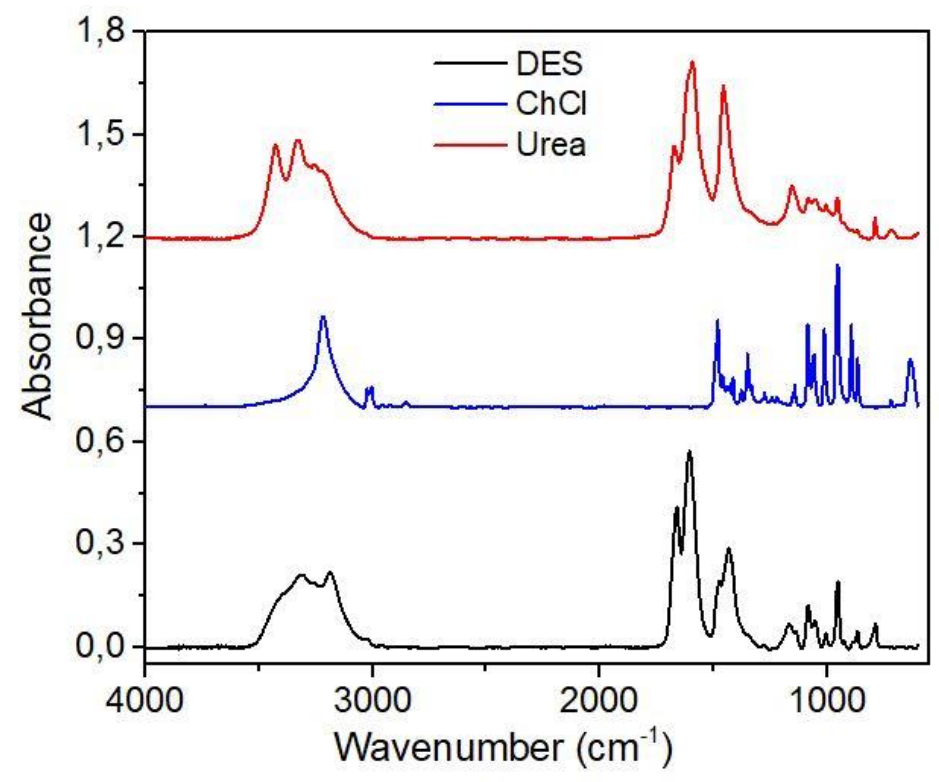

Figure 2 FTIR spectra of choline chloride, urea and synthesized DES

Table 1 Wave numbers and their assignments obtained from FTIR spectra.

\begin{tabular}{|c|c|c|c|}
\hline \multicolumn{3}{|c|}{ Observed frequencies $\left(\mathrm{cm}^{-1}\right)$} & \multirow[t]{2}{*}{ Assignments } \\
\hline Urea & Choline Chloride & DES & \\
\hline 3425 & & 3402 & $V_{a s} \mathrm{NH}_{2}$ \\
\hline 3333 & & 3315 & $v_{s} \mathrm{NH}_{2}$ \\
\hline \multirow[t]{3}{*}{3256} & & & $V_{a s} \mathrm{NH}_{2}$ \\
\hline & 3219 & 3182 & $\mathrm{~V}_{a s} \mathrm{OH}$ \\
\hline & 3016 & 3026 & $\delta_{a s} \mathrm{OH}$ \\
\hline 1674 & & 1665 & $\delta_{a} \mathrm{NH}_{2}$ \\
\hline \multirow[t]{2}{*}{1592} & & 1601 & $\delta_{a s} \mathrm{NH}_{2}$ \\
\hline & 1482 & 1472 & $\rho \mathrm{CH}_{3}$ \\
\hline 1454 & & 1430 & $\rho_{s} \mathrm{CH}_{3}$ \\
\hline \multirow[t]{5}{*}{1151} & & 1169 & $V_{a s} \mathrm{CN}$ \\
\hline & 1086 & 1082 & $\rho \mathrm{CH}_{2}$ \\
\hline & 1008 & 1008 & $v \mathrm{C}-\mathrm{O}$ \\
\hline & 953 & 953 & $v_{a s} \mathrm{CCO}$ \\
\hline & 889 & 870 & Vas $\mathrm{N}-\mathrm{CH}_{3}$ \\
\hline 788 & & 783 & $\omega \mathrm{C}=\mathrm{O}$ \\
\hline
\end{tabular}

In the next step, prepared material was characterized using TEM technique. Figure 3A shows the TEM image of microparticle of $\mathrm{Al}_{2} \mathrm{O}_{3}$ before modification. Figure 3B indicates the apparent presence of gold nanoparticles located over the surface of aluminum oxide. In the results, we confirmed the success of synthesis of gold nanoparticles on $\mathrm{Al}_{2} \mathrm{O}_{3}$ microparticles surface. 

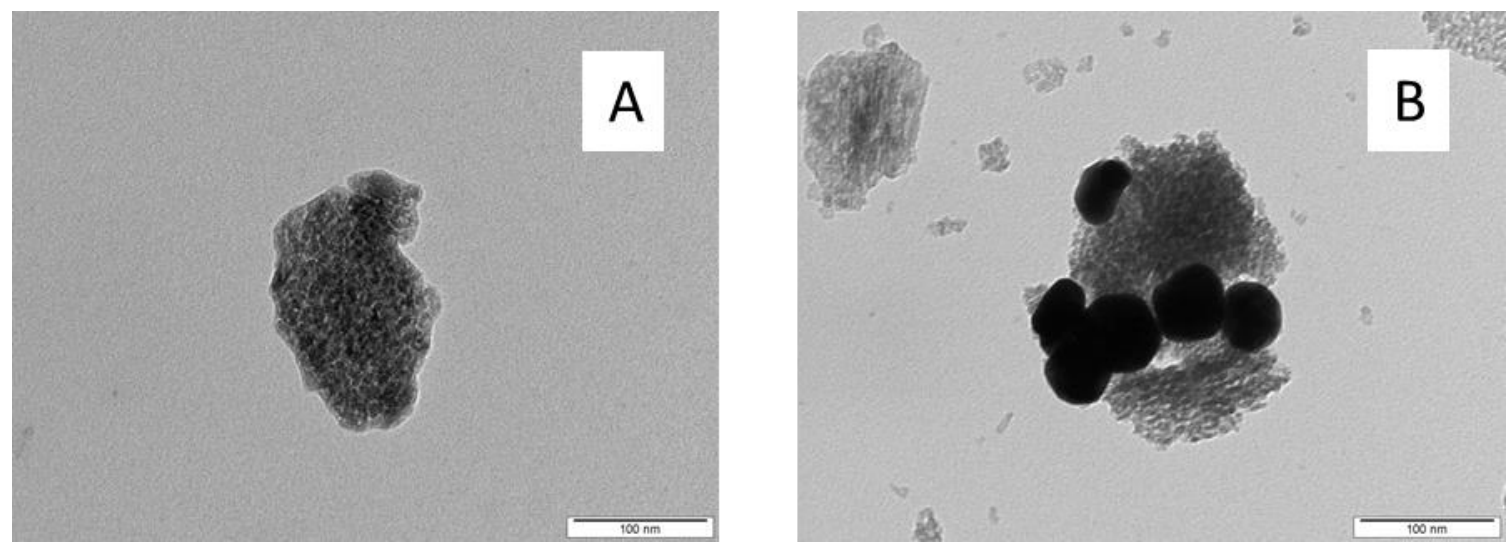

Figure 3 TEM images of $\mathrm{Al}_{2} \mathrm{O}_{3}(\mathrm{~A}), \mathrm{Al}_{2} \mathrm{O}_{3}-\mathrm{AuNPs}(\mathrm{B})$.

The optical characterization of the created system was performed by UV-Vis measurement (Figure 4). The characteristic for pristine $\mathrm{Al}_{2} \mathrm{O}_{3}$ absorption band is located at $260 \mathrm{~nm}$. Synthesis of AuNPs on $\mathrm{Al}_{2} \mathrm{O}_{3}$ surface leads to the appearance of peak with the maximum at $540 \mathrm{~nm}$, which is typical absorption band, characteristic for gold nanoparticles.

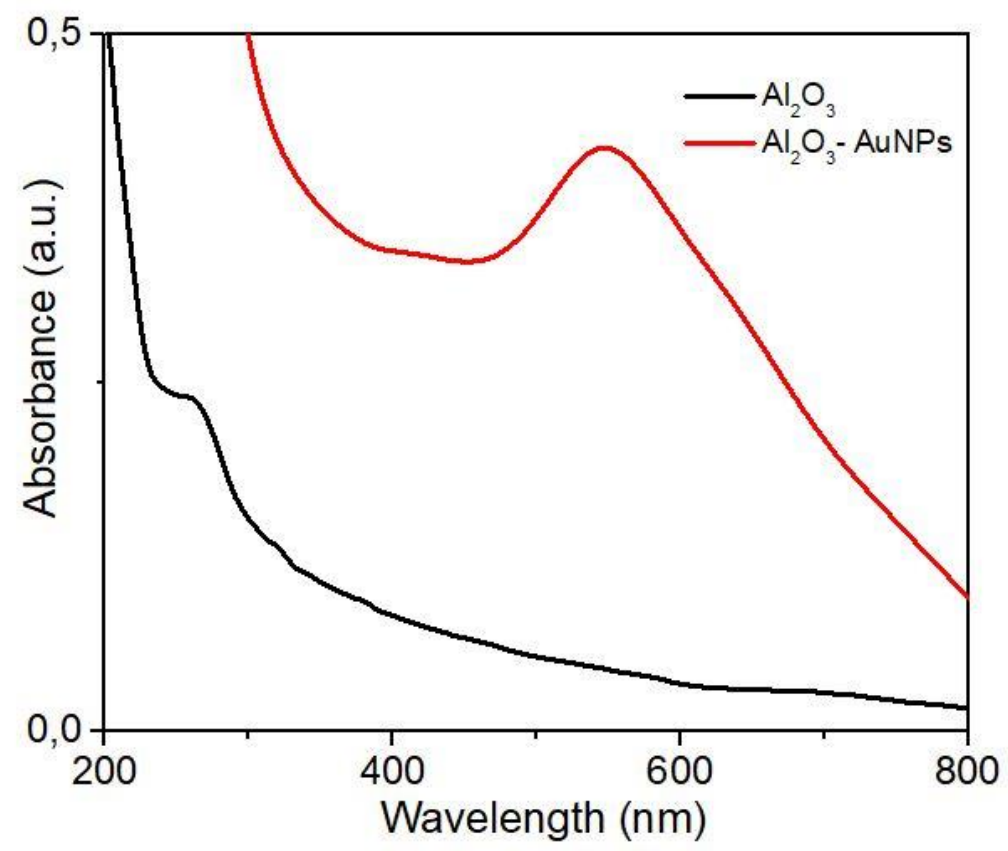

Figure 4 UV-VIS spectrum of $\mathrm{Al}_{2} \mathrm{O}_{3}$ and gold nanoparticles on $\mathrm{Al}_{2} \mathrm{O}_{3}$

\section{CONCLUSION}

In this work, deep eutectic solvent was prepared and doped with metal nanoparticles, previously immobilized on $\mathrm{Al}_{2} \mathrm{O}_{3}$ powder surface. Created system was characterized by FTIR, TEM and UV-Vis method. Such system can be further used for a range of attractive application, with especial attention on green chemistry field.

\section{ACKNOWLEDGEMENTS}

This work was supported by under the project IGA 126882109. 


\section{REFERENCES}

[1] MCCONNELL, W. P., NOVAK, J. P., BROUSSEAU III, L. C., FUIERER, R. R., TENENT, R. C. FELDHEIM, D. L. Electronic and Optical Properties of Chemically Modified Metal Nanoparticles and Molecularly Bridged Nanoparticle Arrays. The Journal of Physical Chemistry B. 2000, vol. 104, pp. 8925-8930.

[2] MITCHELL, M. J., BILLINGSLEY, M. M., HALEY, R. M. Engineering precision nanoparticles for drug delivery. Nature Reviews Drug Discovery. 2021, vol. 20, pp. 101-124.

[3] ZABELINA, A., ZABELIN, D., MILIUTINA, E., LANCOK, J., SVORCIK, V., CHERTOPALOV, S., LYUTAKOV, O. Surface plasmon-polariton triggering of $\mathrm{Ti}_{3} \mathrm{C}_{2} \mathrm{~T} \times \mathrm{MXene}$ catalytic activity for hydrogen evolution reaction enhancement. Journal of Materials Chemistry A. 2021, vol. 9, pp. 17770-17779.

[4] OlshtReM, A., GUSElNIKOVA, O., POSTNIKOV, P., TRELIN, A., YUSUBOV, M., KALACHYOVA, Y., LAPCAK, L., CIESLAR, M., ULBRICH, P., SVORCIK, V., LYUTAKOV, O. Plasmon-assisted grafting of anisotropic nanoparticles - spatially selective surface modification and the creation of amphiphilic SERS nanoprobes. Nanoscale. 2020, vol. 12, pp. 14581-14588.

[5] ZHANG, Q., VIGIER, K., ROYERA, S., JEROME, F. Deep eutectic solvents: syntheses, properties and applications. Chemical Society Reviews. 2012, vol. 41, pp. 7108-7146.

[6] LIAO, H., JIANG, Y., ZHOU, Z., CHEN, S., SUN, S. Shape-Controlled Synthesis of Gold Nanoparticles in Deep Eutectic Solvents for Studies of Structure-Functionality Relationships in Electrocatalysis. Angewandte Chemie. 2008, vol. 120, pp. 9240-9243.

[7] ABBOTT, A. P., TTAIB, K. E., FRISCH, G., RYDERA, K. S., WESTON, D. The electrodeposition of silver composites using deep eutectic solvents. Physical Chemistry Chemical Physics. 2012, vol. 14, pp. $2443-2449$.

[8] ZHU, A., JIANG, T., HAN, B., ZHANG, J., XIEA, Y., MAA, X. Supported choline chloride/urea as a heterogeneous catalyst for chemical fixation of carbon dioxide to cyclic carbonates. Green Chemistry. 2007, vol. 9, pp. 169-172. 